\title{
RICE CROP MONITORING AND YIELD ASSESSMENT WITH MODIS 250m GRIDDED VEGETATION PRODUCT: A case study in Sa Kaeo Province, Thailand
}

\author{
J. S. J. Wijesingha ${ }^{a, *}$, N. L. Deshapriya ${ }^{\text {b }}$ L. Samarakoon ${ }^{b}$ \\ ${ }^{a}$ Department of Physical Geography and Ecosystem Science, Lund University, Sölvegatan 12, S-223 62 Lund, Sweden - \\ jayansrijeewantha@gmail.com \\ ${ }^{\mathrm{b}}$ Geoinformatics Center (GIC), Asian Institute of Technology (AIT), PO Box 04, Klong Luang, Pathumthani, Thailand - \\ lakmal@ait.ac.th, lalsamarakoon@gmail.com
}

KEY WORDS: Rice Phenology, MODIS, NDVI, EVI, Whittaker Smoother

\begin{abstract}
:
Billions of people in the world depend on rice as a staple food and as an income-generating crop. Asia is the leader in rice cultivation and it is necessary to maintain an up-to-date rice-related database to ensure food security as well as economic development. This study investigates general applicability of high temporal resolution Moderate Resolution Imaging Spectroradiometer (MODIS) 250m gridded vegetation product for monitoring rice crop growth, mapping rice crop acreage and analyzing crop yield, at the province-level. The MODIS 250m Normalized Difference Vegetation Index (NDVI) and Enhanced Vegetation Index (EVI) time series data, field data and crop calendar information were utilized in this research in Sa Kaeo Province, Thailand. The following methodology was used: (1) data pre-processing and rice plant growth analysis using Vegetation Indices (VI) (2) extraction of rice acreage and start-of-season dates from VI time series data (3) accuracy assessment, and (4) yield analysis with MODIS VI. The results show a direct relationship between rice plant height and MODIS VI. The crop calendar information and the smoothed NDVI time series with Whittaker Smoother gave high rice acreage estimation (with $86 \%$ area accuracy and $75 \%$ classification accuracy). Point level yield analysis showed that the MODIS EVI is highly correlated with rice yield and yield prediction using maximum EVI in the rice cycle predicted yield with an average prediction error $4.2 \%$. This study shows the immense potential of MODIS gridded vegetation product for keeping an up-to-date Geographic Information System of rice cultivation.
\end{abstract}

\section{INTRODUCTION}

\subsection{Background}

Rice is the second most harvested staple food in the world and the leading staple food in Asia. Rice would be contributes heavily to the alleviation of hunger and poverty since millions of small farmers grow millions of hectares of rice in the Asian region. In addition, there are millions of landless workers who generate some income by working on these farms. Moreover, $60 \%$ of the global population and $90 \%$ of the world rice production is derived from the Asian continent (Claessens, 2013).

Rice monitoring and mapping are thus very important for optimizing food security, environmental sustainability, water security, greenhouse gas emission reduction and general economic prosperity. Most countries in the Asian region use limited survey methods to collect rice paddy data from community level to national level. These data sources do not meet the needs of science and policy researchers, who need geo-spatial databases of rice agriculture with updated spatial and temporal resolution (Xiao et al., 2006).

Remote Sensing is becoming an essential tool for monitoring and mapping rice growing over large areas, at repeated time intervals (Son et al., 2012). According to a review article of Remote Sensing of rice crop areas, Remote Sensing combined with Geographical Information System (GIS) (Kuenzer and Knauer, 2013), can provide reliable information for the following purposes related to rice farming:

- Mapping and monitoring the extent of rice growing ecosystems

\footnotetext{
${ }^{*}$ Corresponding author.
}

- Monitoring and assessment of rice growth and health status

- Assessment of crop pattern and crop system efficiency

- Estimation of crop growth related parameters

- Precision agriculture

- Improvement, and extension of, crop growth and yield models

High temporal and medium spatial resolution optical Remote Sensing Vegetation Indices (VI) known as Normalized Vegetation Index (NDVI) and Enhanced Vegetation Index (EVI) and Land Surface Water Index (LSWI) are utilized to map and monitor rice agriculture on a small scale, and analyzed in a global, continental, and subcontinental context (Sakamoto et al., 2005); (Xiao et al., 2006). Moderate Resolution Imaging Spectroradiometer (MODIS) sensor data was the major data source for those studies. Various time series image analysis techniques, such as wavelet analysis, Artificial Neural Network (ANN), Time Series Regression and Time Series Image Classification, were used to derive rice crop acreage and phenology. (Kuenzer and Knauer, 2013);(Jonai and Takeuchi, 2012);(Sakamoto et al., 2005);(Son et al., 2012);(Xiao et al., 2006).

\subsection{MODIS Gridded Vegetation Product}

The MODIS land science developed Global MODIS VI to provide consistent spatial and temporal comparisons of vegetation conditions. Visible red (620 670nm), near infrared (NIR) (841 $876 \mathrm{~nm}$ ) and visible blue (459 479nm) surface reflectance of MODIS sensor data are used to make global NDVI and EVI products with $250 \mathrm{~m}, 500 \mathrm{~m}, 1000 \mathrm{~m}$, and $5600 \mathrm{~m}$ spatial resolution, and sixteen-day, or one-month temporal resolution. MODIS sensor contains both a Terra and Aqua satellite platform, which were used to make vegetation products MOD13XX and MYD13XX. (The $\mathrm{O}$ refers to Terra platform, the $\mathrm{Y}$ refers to Aqua platform, 
and $\mathrm{XX}$ refers to one letter and one number. For example, if $\mathrm{XX}$ is $\mathrm{Q} 1$, then a sixteen-day composite image with $250 \mathrm{~m}$ resolution is shown. If $\mathrm{XX}$ is $\mathrm{A} 3$, then a one-month composite with $1000 \mathrm{~m}$ resolution is presented). Each year, one satellite sensor provides 23 images of sixteen-day composites. Production of Terra and Aqua products can be improved using the following temporal phase shifts: Terra 16-day period starting day 001, with Aqua 16-day period starting day 009) (Didan et al., 2010).

One Hierarchical Data Format (HDF) data-set in MXD13Q1 provides twelve layers which are NDVI, EVI, Surface reflectance of visible blue, visible red, NIR, Mid-Infrared (MIR) (2105-2155nm), VI Quality Assessment (QA) layer, composite day-of-year layer and four other layers.

MODIS VI data composite algorithm was based on Advanced Very High Resolution Radiometer-NDVI composite algorithm. Constrained View Angle-Maximum Value Composite (CV-MVC) and Bidirectional Reflectance Distribution Function Composite (BEDF-C) were developed by MODIS science team to design MODIS VI. Currently, CV-MVC is used as the primary compositing algorithm for MODIS VI Products (Shao et al., 2011).

NDVI defined by equation (1) is a normalized difference measure, comparing the near infrared and visible red bands defend by equation 1 where ${ }_{\rho} N I R(841-876 \mathrm{~nm})$ and ${ }_{\rho} \operatorname{Red}(620-670 \mathrm{~nm})$ are the bi-directional surface reflectance for their respective MODIS bands. The NDVI is closely correlated with paddy area Leaf Area Index (LAI) (Xiao et al., 2006).

$$
N D V I=\frac{{ }_{\rho} N I R-{ }_{\rho} \operatorname{Red}}{{ }_{\rho} N I R+{ }_{\rho} \operatorname{Red}}
$$

EVI was developed as an alternative vegetation index to NDVI, and is defined in the following equation (2), where ${ }_{\rho} N I R,{ }_{\rho} R e d$, and ${ }_{\rho}$ Blue $(458-479 \mathrm{~nm})$ are atmospherically corrected (or partially atmospherically corrected) surface reflectance, and $C_{1}, C_{2}$, and $L$ are coefficients to correct for atmospheric condition (i.e., aerosol resistance). For the standard MODIS EVI product, $L=1$, $C_{1}=6$, and $C_{2}=7.5$ (Didan et al., 2010).

$$
E V I=G \frac{{ }_{\rho} N I R-{ }_{\rho} \operatorname{Red}}{{ }_{\rho} N I R+C_{1} \operatorname{Red}-C_{2 \rho} B l u e+L}
$$

The MODIS Land VI QA provides quality assurance data for each pixel of the product as a bit field value. Composite dayof-year layer offers information for each pixel, representing the Julian day during the sixteen-day compositing period when reflectance was recorded (Pringle et al., 2012).

The noticeable difference between MODIS NDVI and EVI is the dynamic range. In high bio mass areas, MODIS NDVI appears to be saturated, whereas EVI shows more sensitivity (Shao et al., 2011)

\subsection{Research Problem and Objectives}

National and regional level rice crop monitoring and mapping is not enough to address food security, water management, and environmental stability problems in detail. Provincial or district level crop monitoring and mapping will be an effective way to address the above problems.

A number of studies have involved high level image processing techniques to rice crop monitoring, using satellite data. However, these methodologies were not applied to develop an active upto-date rice crop monitoring system at the provincial- or districtlevel, which can be easily used by government officials as well as administrators to manage and plan rice cultivation.

The specific objectives of this study were to investigate general applicability of high temporal resolution MODIS $250 \mathrm{~m}$ gridded vegetation product for rice crop growth monitoring, rice crop acreage mapping, and yield analysis at the province level. This study addresses the following three primary research questions concerning rice crop monitoring and mapping:

I. How is the rice plant growth illustrated by the Remote Sensing VI?

II. How can you apply Threshold (Beurs and Henebry, 2010) method to determine rice crop information (area, phenology) using MODIS data?

III. How do MODIS NDVI and EVI time series data represent a rice crop and its yield?

To address these questions, a Remote Sensing image analysis was performed combination with statistical analysis using MODIS $250 \mathrm{~m}$ gridded vegetation product data from May to December 2013 across the Sa Kaeo Province in Thailand.

\section{MATERIALS AND METHODS}

\subsection{Study Area}

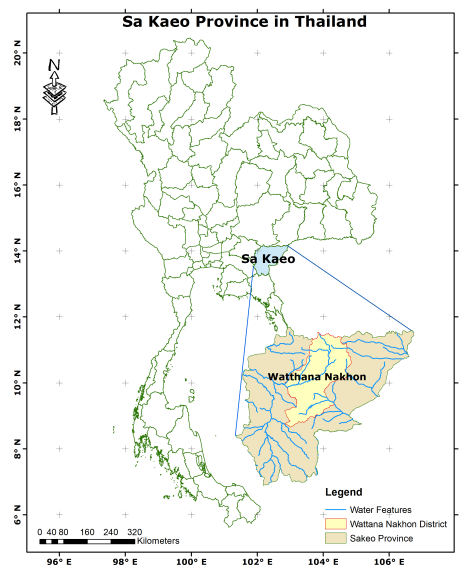

Figure 1: Map of the Sa Kaeo Province and Watthana Nakhon District

The study area for this research work was Watthana Nakhon District $\left(102.4^{\circ} \mathrm{E}, 13.8^{\circ} \mathrm{N}\right)$, Sa Keao Province, Thailand (Figure 1). The northern part of the area includes part of the Thaplan National Park. Paddy, cassava, and permanent crops such as rubber and eucalyptus are cultivated in the central and the southern parts of the district. The paddy agriculture area is flat land with an elevation varying between $10 \mathrm{~m}$ and $100 \mathrm{~m}$. According to 2012/13 agricultural statistics published by the District Agriculture Office, the total agricultural land area is 445053rai (1 rai $=0.16 \mathrm{ha}$ ) and the total area of rice cultivation is 207338 rai. The main rice cultivation season is the wet season, which lasts from May to November and consists of rain-fed water. Dry season rice cultivation is less significant due to lack of water and cultivation of optional crops such as cassava and maze. 


\subsection{Data}

2.2.1 Remote Sensing / GIS Data: MODIS gridded VI product with 250m resolution (MXD13Q1) h27v07 tile was used as the main Remote Sensing data. The VI product data from both Aqua and Terra Satellites (31 images from each platform) was taken over an eight month period (from 2013-05-01 to 2013-1227). Advance Land Observation Satellite (ALOS) global forest/non forest data was used to identify the forest area in the study.

2.2.2 Field Statistics: Filed visit and field data collection was performed at four paddy plots in Watthana Nakhon District over the course of one complete rice cycle, during which time the MODIS satellites were observing the crops. A summary of the field sites is presented in Table 1. Plant height, water level in the field and canals and yield are collected during the field visit. Geotag photographs were taken in every visit to record the change of paddy growth. Province-level agriculture statistics were obtained from the Office of Agriculture Economics and district-level agriculture statistics were provided by the Watthana Nakhon District Agriculture Office.

\begin{tabular}{|l|c|l|l|}
\hline $\begin{array}{l}\text { Site } \\
\text { No }\end{array}$ & \multicolumn{1}{|c|}{ Village } & $\begin{array}{l}\text { Cultivation } \\
\text { started }\end{array}$ & Rice variety \\
\hline 1 & M6 - Ban Nongkum & 10 July & Leuang Awn \\
\hline 2 & M3 - Ban Noongik & 06 July & $\begin{array}{l}\text { Khao Dawk } \\
\text { Mali 105 }\end{array}$ \\
\hline 3 & M14 - Ban Wang Siaw & 07 July & $\begin{array}{l}\text { Khao-Tah } \\
\text { Haeng 17 }\end{array}$ \\
\hline 4 & M9 - Ban Tahg Luang & 04 July & $\begin{array}{l}\text { Khao Dawk } \\
\text { Mali 105 }\end{array}$ \\
\hline
\end{tabular}

Table 1: Summary of the field data collection sites

\subsection{Step Processing}

The whole study can be divided into the following four parts: (1) data pre-processing, (2) rice plant growth analysis using VI, (3) extracting rice crop parameters (e.g. acreage, start-of-season mapping from VI time series and accuracy assessment), and (4) rice yield analysis with MODIS VI.

2.3.1 Data pre-processing: Vegetation index layers (NDVI and EVI), VI QA layer, spectral bands (red, NIR, and MIR), and composite day-of-year layer were extracted from each MODIS HDF product as Geotiff images and then projected to WGS84 geographic projection. Eight days of NDVI and EVI images were stacked as a time series and detailed beyond Sa Kaeo province were masked out. The main element of pre-processing was the smoothing of the time series image stack. The VI time series was smoothed by using modified Whittaker Smoother with negatively biased noise of VI QA values and composite day-of-year values (Atzberger and Eilers, 2011);(Mattiuzzi and Lobo, 2013). Figure 2 shows selected time series before and after smoothing.

2.3.2 Rice plant growth monitoring with RS VI: Rice plant height data from field observation was plotted against extracted corresponding pixel values in VI (NDVI, EVI) data. Rice plant growth and VI pattern was observed.

2.3.3 Extracting Rice Cultivation Parameters: There are several spatio-temporal methods for extracting rice acreage and phenology from VI time series (Kuenzer and Knauer, 2013). This research work utilizes the simple threshold method (Beurs and Henebry, 2010). First, VI time series graphs were plotted for each land cover type (forest, water, urban, and paddy) to identify patterns and determine threshold values. After analyzing each land cover time series graph, an unique pattern was observed in

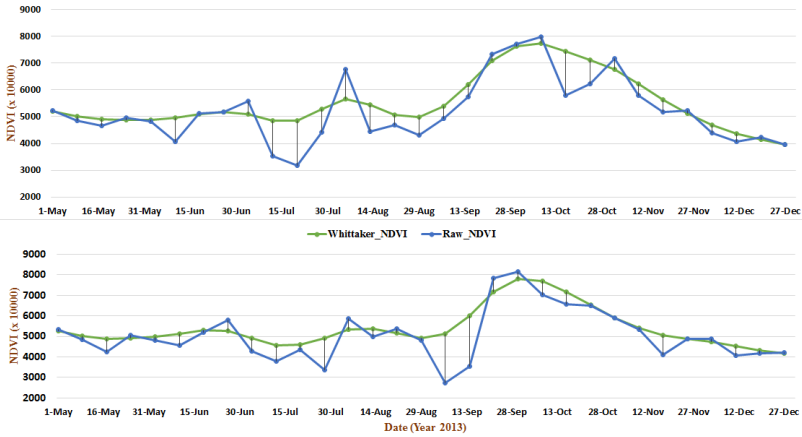

Figure 2: VI time series before and after applying smoothing

the paddy land cover data. Figure 3 and 4 show the how each land cover was interpreted by NDVI and EVI time series. When the rice paddy transitions from vegetative phase to reproductive phase, VI values increase up to a maximum. During the transition from reproductive phase to harvesting, VI values decrease. Paddy rice NDVI and EVI time series profiles therefore exhibit one major peak throughout the season. The date of this maximum is referred to as the heading date. By plotting several paddy pixel time series graphs, the threshold values for extracting paddy area were determined to be 0.6 and 0.47 , for NDVI and EVI respectively.

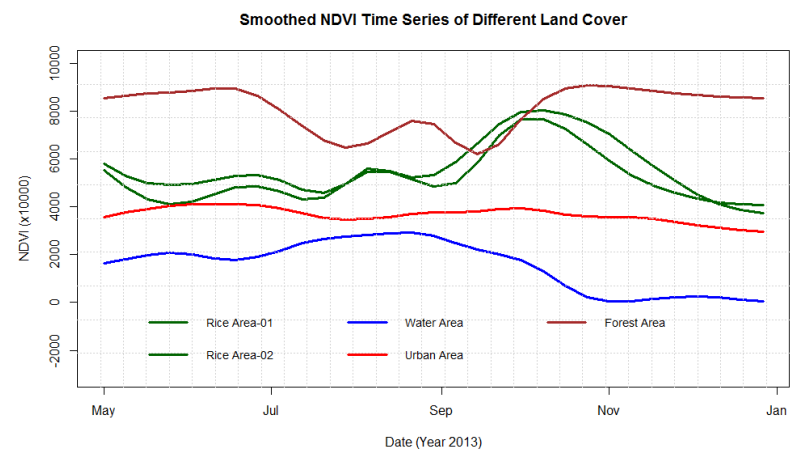

Figure 3: NDVI Time series graphs of different land cover

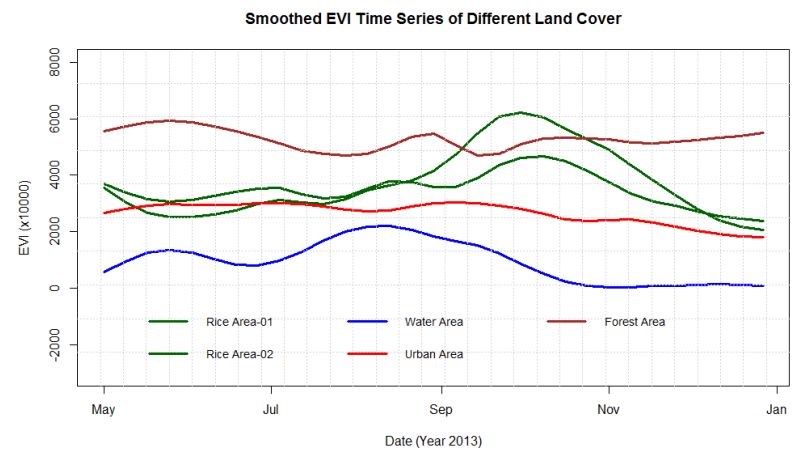

Figure 4: EVI Time series graphs of different land cover

Each time series pixel was analyzed to determine how many peaks exceeded the threshold values for given VI time series. The following information was recorded: number of peak images, first peak date image, second peak date image, and third peak date image. Single peak pixels were considered as single rice crop areas. Null and triple peak pixels reflect non-paddy or non-agriculture areas. Double peak values were further analyzed by calculating 
the difference between the dates of the first and second peaks. If the time difference was more than 80 days, those pixels were considered as representing a double rice paddy. There are two reasons for this condition: (1) a typical rice cycle is about 120 days, and thus cannot be much less than that, and (2) cassava and maze are cultivated with rice as a double crop pattern in some areas of the Sa Kaeo province. ALOS forest cover data was used to mask out the forest area in the study area.

In general, Sa Kaeo province rice cultivation cycle varies from 120 days 140 days. Therefore the rice planting date was occurred 60-70 days before the heading date. The start-of-season for each rice cultivation pixel was calculated by subtracting 70 days from heading date, and start dates were grouped monthly.

Accuracy of rice acreage was measured by comparing provincelevel and district-level rice cultivation area statistics and calculating the confusion matrix and kappa coefficient using ground truth from the field data.

2.3.4 Rice yield analysis with Remote Sensing VI: Chlorophyll content is related to the production of yield of the rice plant and it is reflected by Remote Sensing VI. The VI data was therefore used to determine if there is a correlation between MODIS VI and rice yield, and how the correlation changes with NDVI and EVI. Yield assessment was done using field data gathered from Site 2 and Site 4. The correlation coefficient and liner regression analysis of yield was evaluated against maximum VI of the season, cumulative mean VI of the season, and VI of the flowering date (for both NDVI and EVI). Regression analysis results from each VI were compared to determine which VI was associated with the highest rice yield. The yield of the Site 3 was predicted from the most highly correlated VI model and compared to the actual yield.

\section{RESULTS \& DISCUSSION}
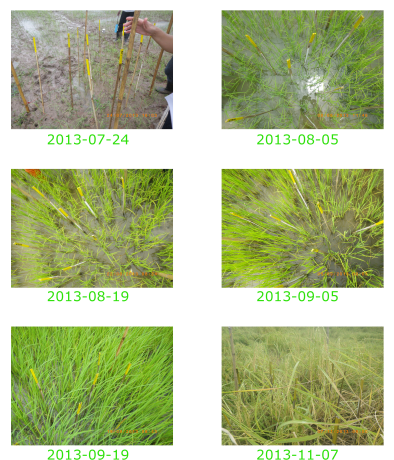

Figure 5: Geo-tag photograph time series of rice paddy cultivation

Rice plant growth observation from the field work is shown in Figure 5. The time series geo-tag photographs clearly show how the plant color changes from light-green to green, and then to yellow.

Figure 6 illustrates rice plant height time series in each field site. According to the time series graph, rice plants grew more than $1.2 \mathrm{~m}$ height and plants grew with approximately uniform speed.

\subsection{Plant height and vegetation indices}

We can observe how VI changes with plant height from the graphs of Figure 7. When plant height reached between $0.7 \mathrm{~m}$ and $1.0 \mathrm{~m}$,

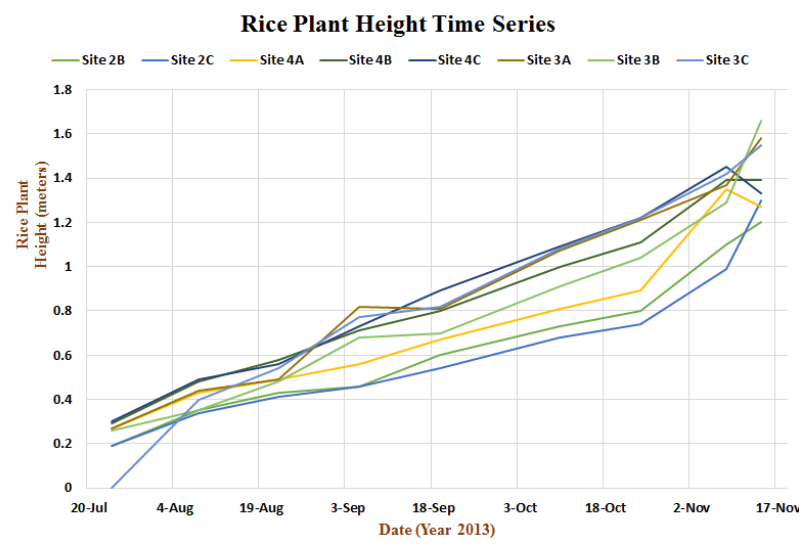

Figure 6: Rice Plant Time Series

NDVI and EVI show their peak values during the plant cycle. However, both NDVI and EVI show a similar pattern in plant height. At the start-of-the season, VI increases with plant height and reaches to peak level, and then it decreases while plant height is increasing.

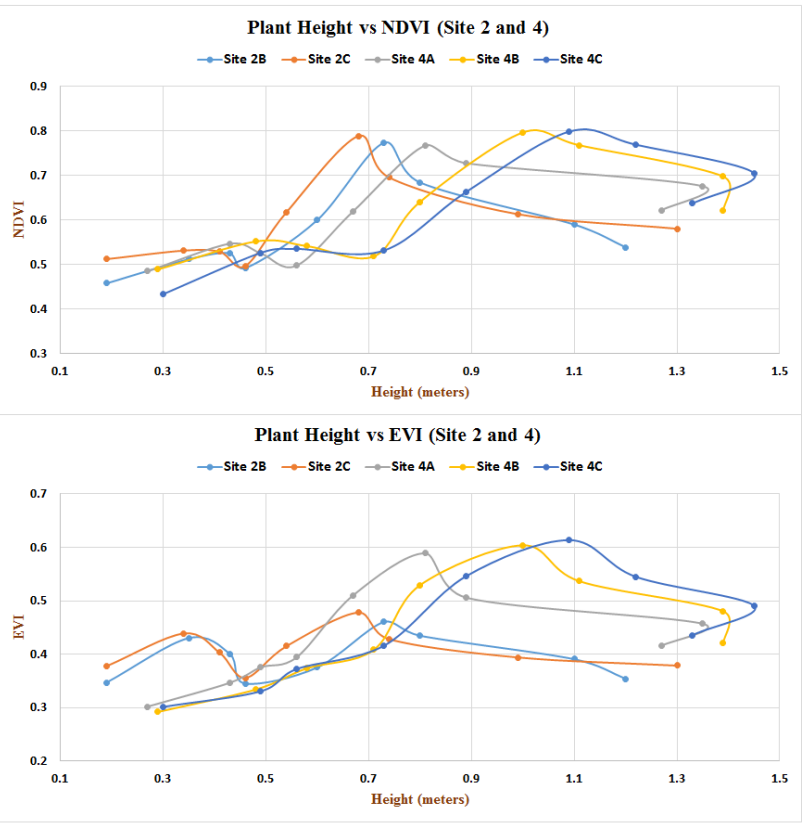

Figure 7: Graph of Rice plant height vs VI (NDVI and EVI)

\subsection{Rice acreage and start-of-season Mapping}

Figure 8 and Figure 9 exhibit NDVI and EVI maps of the rice crop distribution Sa Kaeo Province. Total rice cultivation area in Sa Kaeo province is calculated from both analyses. They are 138795.16ha (NDVI) and 152944.08ha (EVI).

The starting month for single crop areas are shown in Figure 10 and Figure 11. Both NDVI and EVI analyses show more than $80 \%$ of the paddy fields in single crop areas were started in June, July, or August in year 2013.

For both the NDVI and EVI time series analyses of double crop areas, April and May are the starting months for the first cultivation season, and July and August are the starting months for the second cultivation season. 


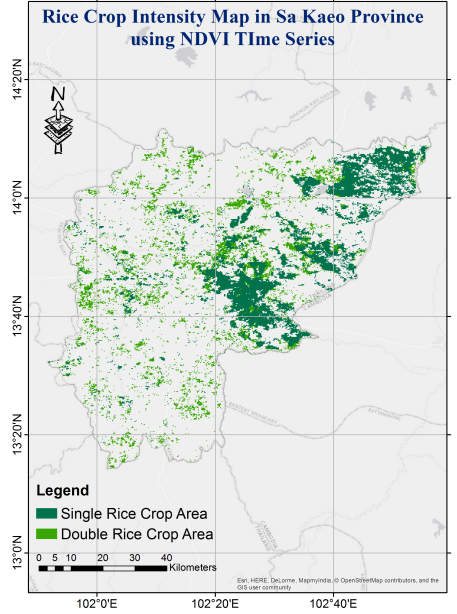

Figure 8: Rice Crop Intensity map from NDVI in Sa Kaeo Province, Thailand)

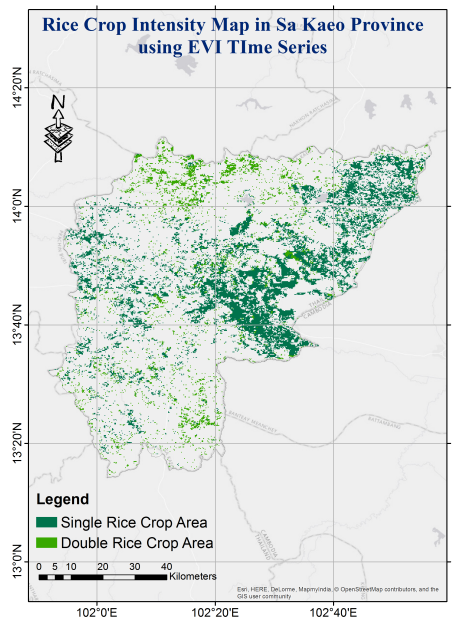

Figure 9: Rice Crop Intensity map from EVI in Sa Kaeo Province, Thailand)

Overall accuracy of NDVI-based rice paddy area mapping is $77.43 \%$ and the Kappa coefficient is 0.55 . The EVI-based rice acreage mapping overall accuracy is $76.47 \%$, with a the Kappa coefficient of 0.52 . The associated confusion matrices from both analyses are shown in Table 2 and Table 3.

\begin{tabular}{|c|c|c|c|c|}
\hline NDVI & Non Paddy & Paddy & Total & P. Acc. $(\%)$ \\
\hline Non Paddy & 89 & 19 & 108 & 82.41 \\
\hline Paddy & 32 & 86 & 118 & 72.88 \\
\hline Total & 121 & 105 & 226 & \\
\hline U. Acc. (\%) & 73.55 & 81.90 & & \\
\hline O. Acc. (\%) & 77.43 & & & \\
\hline Kappa & 0.55 & & & \\
\hline
\end{tabular}

Table 2: Accuracy assessment of NDVI-based rice acreage mapping

Province-level rice acreage was calculated by comparing the VIdetermined acreage with the statistics provided by the Office of Agriculture Economics. Total acreage determined by NDVI was

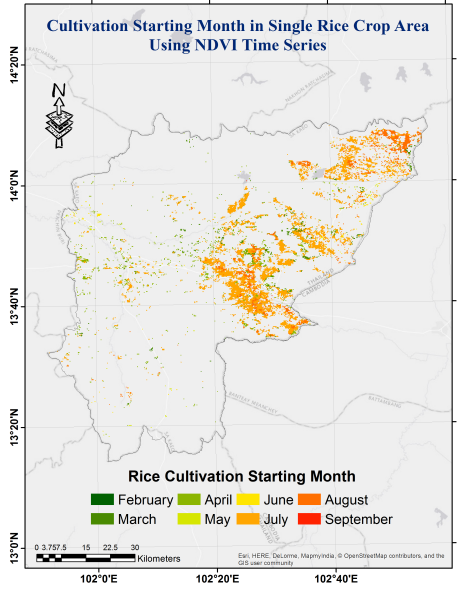

Figure 10: Single rice crop area start-of-season in Sa Kaeo Province, using NDVI

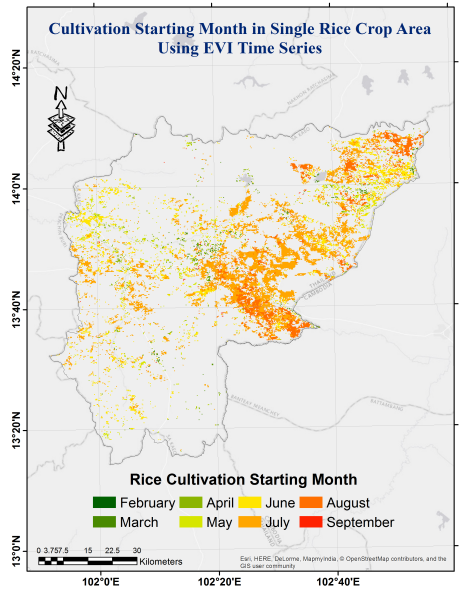

Figure 11: Single rice crop area start-of-season in Sa Kaeo Province, using EVI

\begin{tabular}{|c|c|c|c|c|}
\hline EVI & Non Paddy & Paddy & Total & P. Acc. $(\%)$ \\
\hline Non Paddy & 100 & 34 & 134 & 74.63 \\
\hline Paddy & 18 & 69 & 87 & 79.31 \\
\hline Total & 118 & 103 & 221 & \\
\hline U. Acc. (\%) & 84.75 & 66.99 & & \\
\hline O. Acc. (\%) & 76.47 & & & \\
\hline Kappa & 0.52 & & & \\
\hline
\end{tabular}

Table 3: Accuracy assessment of EVI-based rice acreage mapping

138795ha, and total acreage determined by EVI was 152944ha. These estimates deviate from the published statistics by +3529 ha (NDVI) and +17678 ha (EVI), producing relative error of $2.6 \%$ (NDVI), and $13.1 \%$ (EVI). At the district-level, rice acreage accuracy was calculated by comparing the VI-determined acreage with the statistics reported by Watthana Nakhon District Agriculture Office. Rice cultivation area within Watthana Nakhon District is 33174 ha. However, the district rice acreage determined by NDVI was only $29491 \mathrm{ha}$, and the district acreage determined by EVI was only 31916 ha, producing relative error of $11.1 \%$ (NDVI) and $3.8 \%$ (EVI). These statistics suggests rice acreage can be esti- 
mated by NDVI and EVI with in $14 \%$ maximum deviation. Confusion matrix analysis shows that rice acreage estimation using NDVI and EVI has an accuracy of more than $75 \%$. Table 4 summarizes the area-based accuracy.

\begin{tabular}{|c|c|c|r|r|}
\hline Level & Area (ha) & Method & Estimated (ha) & RE (\%) \\
\hline \multirow{2}{*}{ Province } & \multirow{2}{*}{135265.60} & NDVI & 138795.16 & -2.61 \\
\cline { 3 - 5 } & & EVI & 152944.08 & -13.07 \\
\hline \multirow{2}{*}{ District } & \multirow{2}{*}{33174.08} & NDVI & 29490.81 & +11.10 \\
\cline { 3 - 5 } & & EVI & 31916.44 & +3.79 \\
\hline
\end{tabular}

Table 4: Summary of the area based accuracy assessment

\subsection{Yeild Analysis}

Rice yield and NDVI/EVI correlation analysis was done in three different ways. First, a correlation and linear regression analysis was performed using maximum VI of the time series and the yield. For the yield with maximum NDVI and maximum EVI, the correlation coefficient were 0.45 and 0.98 , respectively. Analysis shows that the maximum EVI has the highest correlation with yield. The R-square values from linear regression analysis are 0.2 (NDVI) and 0.95 (EVI).

Second, the correlation between yield and flowering date VI was investigated. The average flowering date was founded by a survey done on farmers and it was on the 14th October, 2013. The $\mathrm{R}^{2}$ values for linear regression are 0.72 (NDVI) and 0.92 (EVI). Table 5 summarizes regression analysis results of the above two methods.

\begin{tabular}{|l|c|r|}
\hline \multicolumn{1}{|c|}{ Method } & VI & $\mathbf{R}^{2}$ Value \\
\hline \multirow{2}{*}{ Maximum VI } & NDVI & 0.20 \\
\cline { 2 - 3 } & EVI & 0.95 \\
\hline \multirow{2}{*}{ Flowering Date VI } & NDVI & 0.72 \\
\cline { 2 - 3 } & EVI & 0.93 \\
\hline
\end{tabular}

Table 5: Regression for yield with maximum VI and flowering date VI

A third yield analysis compared yield and cumulative mean of VI. Cumulative VI mean was calculated for the eight days after the start-of-season. The correlation coefficient of each cumulative VI mean and yield was also calculated. The cumulative VI with highest correlation coefficient was used in a regression analysis of the yield. Figure 12 illustrates how the correlation coefficient changes with cumulative NDVI/EVI and yield. Both NDVI and EVI exhibits a similar pattern of correlation coefficient; both VI are negatively correlated with yield at the start of the season, and then become positively correlated, with high correlation coefficient values.

Regression analysis results of the highest correlation between cumulative mean VI and yield are described in Table $6 . \mathrm{R}^{2}$ values from linear regression analysis are 0.71 (NDVI) and 0.87 (EVI).

\begin{tabular}{|c|r|r|}
\hline VI & Highest CC & $\mathbf{R}^{2}$ Value \\
\hline NDVI & 0.84 & 0.71 \\
\hline EVI & 0.94 & 0.88 \\
\hline
\end{tabular}

Table 6: Regression analysis results of highest correlated cumulative mean VI with yield

The results of all three yield analyses show that yield has a higher correlation with EVI than NDVI. The $\mathrm{R}^{2}$ values of regression analysis with yield are 0.95 (for maximum EVI), 0.93 (for flowering dates EVI), and 0.88 (for cumulative mean EVI).

The highest correlated EVI was utilized to predict yield for Site 3 , which was then compared with actual yield. The most precise

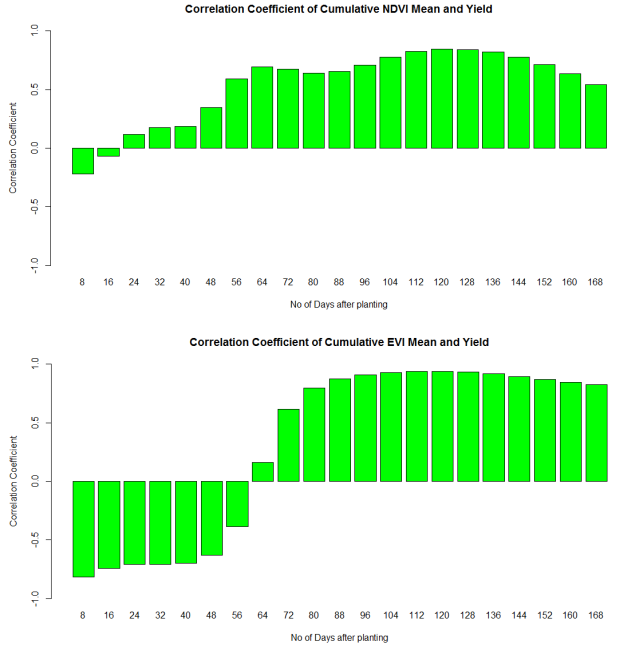

Figure 12: Correlation coefficient changing graph of the Cumulative VI mean and yield)

prediction is given by the maximum EVI of the time series, with an average error of $4.21 \%$. The flowering data EVI also give better results (5.62\% error) than cumulative mean EVI $(10.87 \%)$. Figure 13 compares the actual yield with EVI-predicted yield.

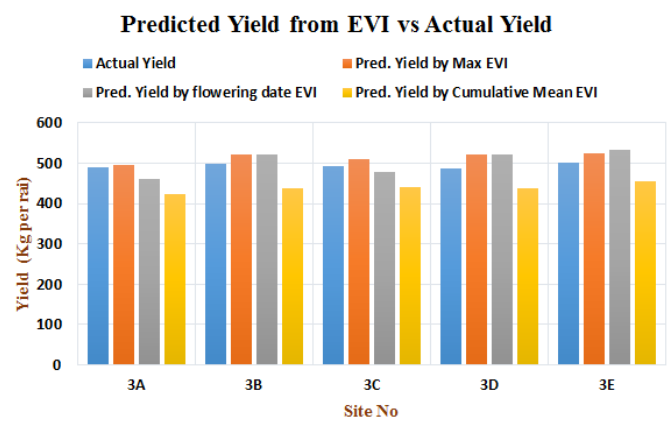

Figure 13: Actual yield and predicted yield from EVI by different method in Site 3)

\section{CONCLUSION}

This study illustrates the significant potential of using MODIS data for rice crop monitoring. MODIS 250m gridded vegetation NDVI and EVI data from both sensors (Aqua and Terra) increase the frequency of observation and improve rice monitoring. The use of the Whittaker smoothing technique, which includes a combination of quality assessment data and $\mathrm{R}$ program library, is recommended (Atzberger and Eilers, 2011).

The results obtained by this research confirm that there is an observable relationship with rice plant growth and VI changes in rice paddy land cover. MODIS NDVI and EVI rice paddy acreage mapping (using the Threshold method and crop calendar data) gives a minimum of $86 \%$ area accuracy and $75 \%$ classification accuracy. Rice crop cultivation starting month extracted via MODIS NDVI data matched the field data. MODIS NDVI data is better than EVI for rice acreage mapping and start-of-season mapping.

Pixel level yield analysis shows yield and VI have a noteworthy relationship. EVI is better for yield analyzing and Maximum VI 
throughout the crop season which indicates the highest correlation with yield. Yield was predicted for site 03 with $4.2 \%$ error using maximum EVI of the season.

It was proved that time series MODIS $250 \mathrm{~m}$ vegetation index product data has immense potential for monitoring rice crops. This study shows the usefulness of MODIS gridded vegetation product for the following techniques: (1) mapping rice cultivation area at the province-level, (2) generating an up-to-date database of rice acreage and start-of-season dates, and (3) predicting yield of rice crop before harvesting. Applying this novel methodology for implementing up-to-date GIS rice database is recommended for other areas where rice cultivation is prominent.

\section{ACKNOWLEDGEMENTS}

The authors thank Ms. Udompna Promnart of the Prachinburi Rice Research Center, Thailand, whose enormous support made this field work possible. The authors are also grateful for assistance from Watthana Nakhon District Agriculture Office staff, and from the village leaders and farmers.

\section{REFERENCES}

Atzberger, C. and Eilers, P., 2011. A time series for monitoring vegetation activity and phenology at 10-daily time steps covering large parts of South America. International Journal of Digital Earth 4(5/5), pp. 365-386.

Beurs, K. D. and Henebry, G., 2010. Spatio-Temporal Statistical Methods for Modelling Land Surface Phenology. In: Hudson I.L. and M. R. Keatley (eds), Phenological Research, Springer, Netherlands.

Claessens, G., 2013. IRRI's Rice Production Course. Online.

Didan, K., Solano, R., Jacobson, A. and Huete, A., 2010. MODIS Vegetation Index User's Guide - Version 2.00.

Jonai, H. and Takeuchi, W., 2012. Development of new water index with modis and amsr-e for global rice paddy field mapping. In: Proceedings of 34th Asian conference on remote sensing (ACRS), AARS.

Kuenzer, C. and Knauer, K., 2013. Remote Sensing of rice crop areas. International Journal of Remote Sensing 34(6/12), pp. 2012-2139.

Mattiuzzi, M. and Lobo, A., 2013. Filter vegetation index time series imagery with the modified whittaker approach.

Pringle, M., Denham, R. and Devadas, R., 2012. Identification of cropping activity in central and southern Queensland, Australia, with the aid of MODIS MOD13Q1 imagery. International Journal of Applied Earth Observation and Geoinformation 19, pp. 276-285.

Sakamoto, T., Yokozawa, M., Toritani, H., Shibayama, M., Ishitsuka, N. and Ohno, H., 2005. Remote Sensing of Environment (3/4), pp. 366-374.

Shao, Y., Taff, G. and Lunetta, R., 2011. A Review of Selected MODIS Algorithms, Data Products, and Applications. In: Q. Weng (ed.), Advances in Remote Sensing, CRC Press LLC, Boca Raton, Florida.

Son, N., Chen, C. and Cru, C., 2012. Mapping major cropping patterns in Southeast Asia from MODIS data using wavelet transform and artificial neural networks. International Archives Photogramm. Remote Sensing XXXIX-B3, pp. 421-425.
Xiao, X., Boles, S., Frolking, S., Li, C., Babu, J., Salas, W. and Moore, B., 2006. A crop phenology detection method using timeseries modis data. Remote Sensing of Environment 96(1), pp. 95113.

Revised March 2015 